\title{
Optimization of the Accuracy of Semi-Indirect Energy Metering System
}

\author{
G. M. N. K. Kumara Galathara, Lalith A. Samaliarachchi and S. M. D. P. K. \\ Sooriyadasa
}

\begin{abstract}
Difference between a measurement reading and the true value of that measurement is known as accuracy. The measuring device or system should have the capability to measure and match the actual value to the quantity that is being measured to an acceptable accuracy declared by respective standards. Measurements of electrical energy in various demand categories of different utilities have their own limits. The employed measuring system is designed according to the demand category. Semi indirect metering system is being used to measure energy consumed between $42 \mathrm{kVA}$ to 1 MVA by the governing Sri Lankan utility, Ceylon Electricity Board (CEB). It requires a current transformer (CT), an energy meter and lead wires only. In general, such systems are installed after certain standard checkups carried out for individual accuracy of CTs and energy meters in a standard testing laboratory. However, it has been observed that there is a considerable deviation of accuracy than expected when considering the accuracy of the whole system setup. Replacing of analogue meters by digital meters in semi indirect measuring environment to establish an automated meter reading system by a Utility has exclusive advantages such as immunity tamper up to certain extent and features supported by enhance data communication facilities etc. However, careful study is required to omit the potential of getting deviated the total system error beyond the desired limits due to the burden mismatch owing to CTs, energy meters and associated lead wires. In this research study, it was observed that considerable percentage of semi indirect metering systems installed are operating at under burden condition. The study focused to minimize the error deviation of semi indirect metering system owing to the above mentioned factors with a new concept of appropriate burden matching. The study also concentrated on to finding the factors affecting the accuracy and how to eliminate the error through a simple error compensation method. In here all the experiments were done in the laboratory for 100/5 semi indirect metering model and it describes the methodology for improving the accuracy clearly by appropriate component selection using developed charts for different contract demands operating at different power factors depending on the application.
\end{abstract}

Keywords: Semi-indirect metering system, burden matching, error compensation

\section{Introduction}

\section{$1.1 \quad$ Objective}

Electricity metering system can be classified in to:

- Direct metering (using energy meter only)

- Semi-indirect metering (using energy meter with a CT)

- Indirect metering (using energy meter, $\mathrm{CT}$ and a voltage transformer)

Categorization of the metering system in case of CEB, depending on the consumer contract demand (D) is as follows:

- Direct metering $(\mathrm{D}<42 \mathrm{kVA}$ at $400 \mathrm{~V})$

- Semi-indirect metering $(42 \mathrm{kVA}<\mathrm{D}<1000$ kVA at $400 \mathrm{~V}$ )

- Indirect metering $(\mathrm{D}>1000 \mathrm{kVA}$ at $11 \mathrm{kV}$ or $33 \mathrm{kV}$ )
This paper discusses the methodology for minimizing the error band of the existing semiindirect energy measuring system by:

- Shifting the operating current of CTs in to the best performance region.

- Matching the secondary burden of the CTs by appropriate lead wire lengths.

- Development of chart based tables for the selection of lead wire lengths for predetermined accuracy.

G.M. N. K. Kumara Galathara, NDT (Moratuwa)

B. Tech. Eng (Under Graduate), Open University of Sri

Lanka (OUSL), Electrical Superintendent, Meter Testing

Laboratory DD-1, Ceylon Electricity Board(CEB)

Eng. Lalith A. Samaliarachchi, B.Sc. Eng. (Hons) (Moratuwa), M. Eng.(AIT), MIEE(UK), MIE(Sri Lanka), C.Eng Senior Lecturer, Department of Electrical $\mathcal{E}$ Computer Engineering, OUSL

Eng. S.M.D.P.K. Sooriyadasa, B.Sc. Eng. (Peradeniya), AMIE (Sri Lanka), Electrical Engineer, Meter Testing Laboratory DD-1, (CEB) 


\subsection{Background}

Electro-mechanical meters were used for semiindirect metering system during past few decades in Sri Lanka. Two types of analogue meters are widely being used in this regard to measure electrical energy $(\mathrm{kWh})$ and Maximum electricity demand (kVA). Table 1 shows the meter specifications.

Table 1 - Analogue meter specifications

\begin{tabular}{|c|c|c|c|c|}
\hline $\begin{array}{c}\text { Unit } \\
\text { Type }\end{array}$ & $\begin{array}{c}\text { Meter } \\
\text { Type }\end{array}$ & $\begin{array}{c}\text { Accuracy } \\
\text { Class }\end{array}$ & $\begin{array}{c}\text { Burden } \\
\text { (VA) }\end{array}$ & Remarks \\
\hline kWh & GEC & 2 & 2.5 & N/A \\
\hline kVA & $\begin{array}{c}\text { Landis } \\
\text { \& Gyr }\end{array}$ & 2 & 2.5 & $\begin{array}{c}\text { Accuracy valid } \\
\text { between } \\
\text { pf }=0.67-0.98\end{array}$ \\
\hline
\end{tabular}

Replacement of analogue bulk energy meter set with solid state meters result distinguished improvements, in accuracy perspective. However, it has shown certain inaccuracies owing to the associated component mismatch burdens such as CTs, meters and lead wires. It is well known to the public and to the utility that the revenue and loss calculations, demand forecasting and end user satisfaction depend upon the accurate metering system. Hence any fine improvement to an existing metering system will be an effective contribution to the development of any utility.

\subsection{Existing System}

Figure-1 shows the schematic diagram of semiindirect metering system currently being practised by Sri Lankan institutions that have the distribution licensees. Current transformers, energy meters and lead wires are the main components of this system.

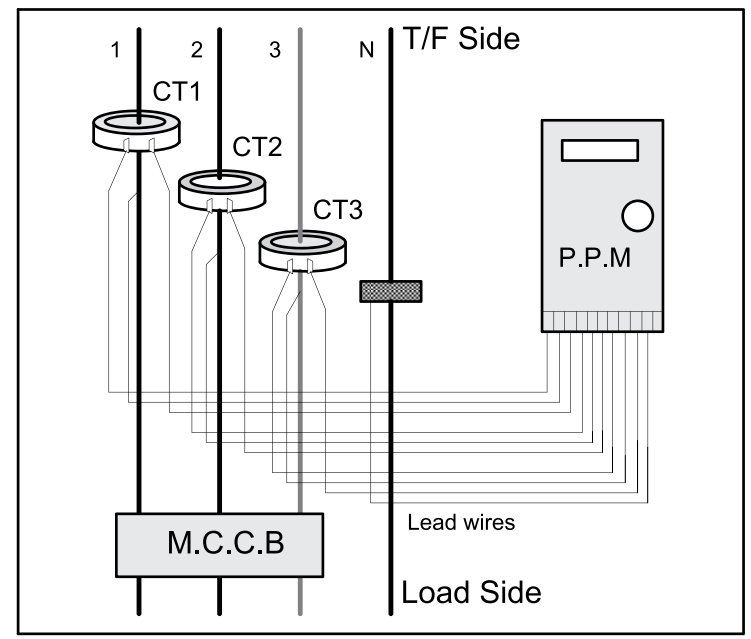

Figure 1-Schematic diagram of the Semi-indirect metering system

\subsection{Energy Meters}

The energy meters installed are of Programmable Polyphase Meters (PPM) of accuracy class 1 with remote meter reading facility [1]. EDMI and PREMIER are the main brand types available in Sri Lanka having burden of 0.5 VA under extreme operating conditions.

\subsection{Current Transformers}

Accuracy improvement of the semi indirect metering system is heavily depends upon the CT specification as per the IEC regulations [6]. Table 2 shows the types of CTs that are widely being used in Sri Lanka for Semi-indirect metering system. It should be noted that the very first metering point is where the $\mathrm{CT}$ is installed. Hence the performance characteristics of CTs are identified as the critical and most important area in this research study.

Table 2 - Types of Current Transformers

\begin{tabular}{|c|c|c|}
\hline Type & $\begin{array}{c}\text { Accuracy } \\
\text { Class }\end{array}$ & Burden (VA) \\
\hline ITL & $1 / 0.5 / 0.2$ & $15 / 5 / 2.5$ \\
\hline Horbut & $1 / 0.5 / 0.2$ & $15 / 5 / 2.5$ \\
\hline ARW & $1 / 0.5 / 0.2$ & $15 / 5 / 2.5$ \\
\hline Wong Young & $1 / 0.5$ & $10 / 5$ \\
\hline
\end{tabular}

Burden of a CT is defined as the apparent power in volt-amperes absorbed at specified power factor at its rated secondary current or in other words it is the maximum load that the CT secondary can handle (Meter and lead wire) [6]. Further the ratio error of a CT is defined as:

Ratio Error $=\frac{\left(\mathrm{CT} \text { ratio } \times \mathrm{I}_{\text {secondary }}-\mathrm{I}_{\text {primary }}\right)}{\mathrm{I}_{\text {primary }}} 100 \%$

Phase displacement error of a CT is the difference in phase displacement between the primary and secondary current vectors [6]. Figure 2 and 3 shows the variation of ratio error (\%) and displacement error (min) against the nominal current for a CT-ARW Class-1. It also shows that the ratio error increases negatively and displacement error increases positively while varying the nominal current from $2.5 \% \mathrm{I}_{\mathrm{n}}$ to $120 \%$ In respectively. Total error comes out to be the contribution of both ratio error and phase displacement error. 


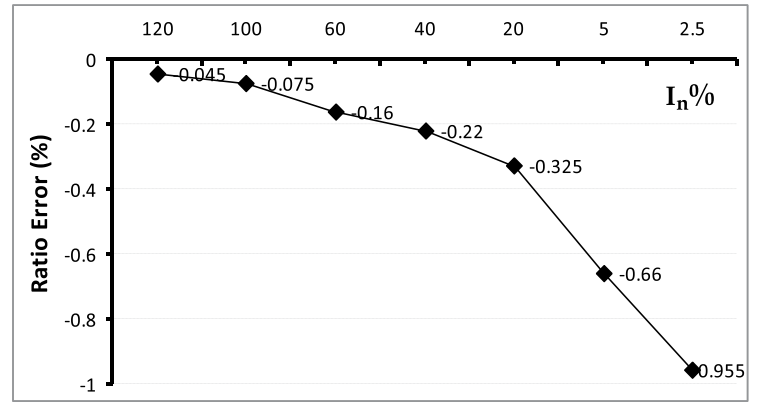

Figure 2 - Ratio Error variation

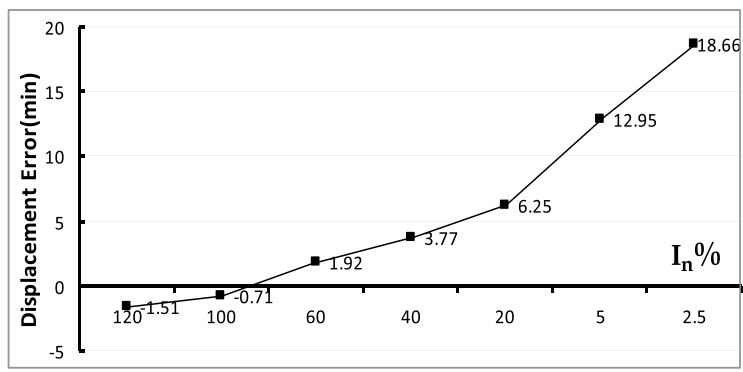

Figure 3 - Displacement Error variation

\subsection{Lead Wires}

Even though the lead wire length selection process is not well defined in the respective specifications used by the utilities, for example CEB 57:1997 states that the cross sectional area of the connecting cables should not be less than $2 \mathrm{~mm}^{2}$ [3]. Under the circumstances, an established method has not been practised so far and moreover, there is not much of an attention is given technically when selecting the lead wire lengths in burden matching perspective. Most of the installations are observed to be carried out using $2.5 \mathrm{~mm}^{2}$ or 1 $\mathrm{mm}^{2}$ double insulated multi strand wire lengths. Also, it is worthwhile to note at this point that the Lead wires not only affect the CT burden but also exposed for tampering. Therefore the lead wire selection for semi indirect metering system is an important exercise to be observed very carefully.

\subsection{Semi-indirect metering system data}

A comprehensive survey was carried out at randomly selected factories in Kurunegala area to analyse the present situation of semi indirect metering system. Data collection was done by visiting each location. Appendix-A, Table-A1 shows the technical details gathered. Onsite testing was carried out by using high precision portable test equipment (Zera MT 310, class-1) to measure the energy meter accuracy, overall error and instant parameters. Average power factor and average load were obtained by the load survey of PPM. Here it was observed that the burden of all CTs is 15VA and burden of meters is $0.5 \mathrm{VA}$. Wire lengths are observed to be almost around $1 \mathrm{~m}$ and average power factors were more than 0.89 . Operating current $\left(\% \mathrm{I}_{\mathrm{n}}\right)$ was observed to be very much lower with respect to the rated current of CTs. Although the overall error of semi-indirect metering system at the surveyed location were approximately around $3 \%$, the individual error of the energy meters were within the class of 0.5 , thereby the additional error was introduced into the system by CTs and lead wires.

\subsection{Ferraris Vs solid state meters}

Modernization replaced the classical induction meters by solid-state meters. Besides ensuring precise metering, latter enables remote meter reading and various metering systems such as Automatic Metering Management (AMM). In addition to the expanded functions, they differ from the Ferraris in terms of electrical properties, and particularly their selfconsumption (meter burden). Since in the course of years electrical properties such as transformation ratio, instrument security factor etc. of measuring VTs and CTs remain more or less unchanged for the majority of end users, their measuring properties are mostly effected by under-burdening of the secondary circuit caused by replacement of the Ferraris meters by the electronic ones. Normally the power consumption of electronic meters is from five to ten times smaller compared to the Ferraris meters [7],[8]. Specification of VA burdens of CTs often come across with specified values of $2.5,5,10,15 \mathrm{VA}$. These burden values arrived at the specifications are decided or documented by end users, project engineers, process consultants and engineering consultants by making hypothetical burden calculations \& inflating the values. These methods invariably lead to select inappropriate burden values of CTs thus leading to inaccurate reading. Old bulk supply metering system (>42kVA) consisted of two separate meters for active and apparent energy measurement where the burden of metering path is much higher with respect to that of static meters. Thus, when replacing two analogue meters with a single digital meter, the operating burden of secondary circuits of measuring CTs get further lowered.

\subsection{Literature Survey}

Neither any technical literature found nor any research work has been carried out so far as to analyse the performance of the present 
situation. Only routine tests had been carried out to verify the energy meter accuracy only. However, it was observed while surfing the internet that Slovenia and India has faced similar under burden miss-matching metering condition due to replacement of Ferraris meters by solid state meters as in Sri Lanka [4].

\section{Theoretical Analysis}

\subsection{Effect of the secondary burden}

Practically, the primary and secondary ampereturns are not exactly equal in CTs. Depending on the core material used; some of the primary ampere-turns will be used to excite the core. Only the remaining primary ampere-turns will be available for transformation. Thus, the required primary ampere-turns are invariably become less and it creates an error in the operation of CTs. Figure 4 shows an equivalent circuit of an ideal CT and it explains how it would create an error owing to burden mismatch.

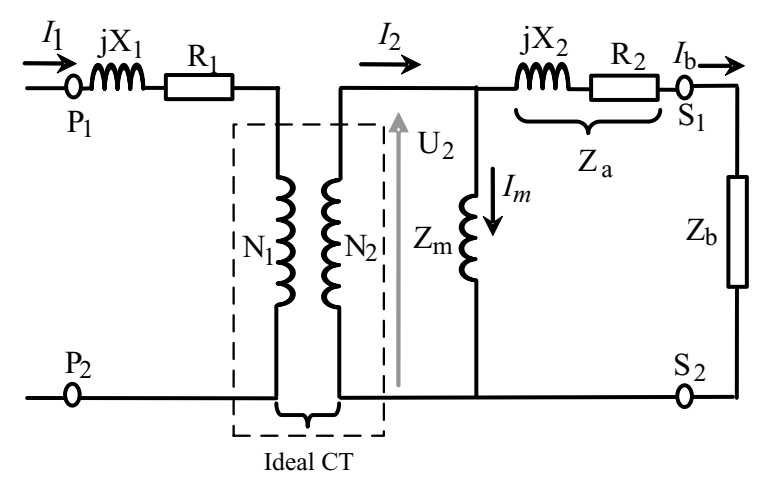

Figure 4 - Equivalent circuit of a CT

Symbols on the figure carry their usual meanings and $Z_{b}$ represent the secondary load. Simplified secondary side of the equivalent circuit can be represented as shown in Figure 4 . $\mathrm{Z}_{\mathrm{m}}$ is the magnetization impedance and it is assumed to be a constant. Note that the secondary burden is represented by $Z_{a}+Z_{b}$ i.e. secondary impedance + burdens of the meter + lead wire. When the secondary burden of the CT varies, it directly affects the secondary current and phase displacement. Accordingly, the accuracy of the $\mathrm{CT}$ operated metering system varies.

$$
I_{b}=\left(\frac{Z_{m}}{Z_{x}+Z_{m}}\right) I_{2}
$$

Where $Z_{x}=Z_{a}+Z_{b}$
$Z_{x}=Z_{a}+Z_{b}$ can be varied when vary the lead wire length/cross section. When the wire length $Z_{b}$ increases, $I_{b}$ get decreases. With this low burden condition, positive deviation of accuracy can be observed. According to the above analysis over burden condition may lead to make negative error of accuracy. In this project, lead wire length was varied and selected the best cross sectional area to give the sufficient burden for secondary.

Lead wire burden in VA $=\frac{\mathrm{I}^{2} \times 2 \mathrm{D}}{\mathrm{CS} \times \sigma}$

Where:

$$
\begin{aligned}
& \mathrm{I}=\text { Secondary current } \\
& \mathrm{D}=\text { Lead wire distance in meter. } \\
& \mathrm{CS}=\text { Cross section area of lead wire } \\
& \sigma \quad=\text { Conductivity of copper }
\end{aligned}
$$

\subsection{Effect of the primary power factor}

This is a theoretical innovative explanation carried out in this section of the research to illustrate the effect of primary power factor on the accuracy of CTs. Practically the transformation ratio of a CT is 1: N. Figure 5 shows the single line diagram of a CT referred to primary side. Practically current transformer does not reflect the primary phase angle to the secondary side as it is. It allways gives a leading power factor error. Figure 6 vector diagram represents the magnitude and phase displacement error of two states of primary power factors bold and normal. The reflected magnitude component is smaller when primary power factor decreases but power factor improves due to adding of phase displacement error.

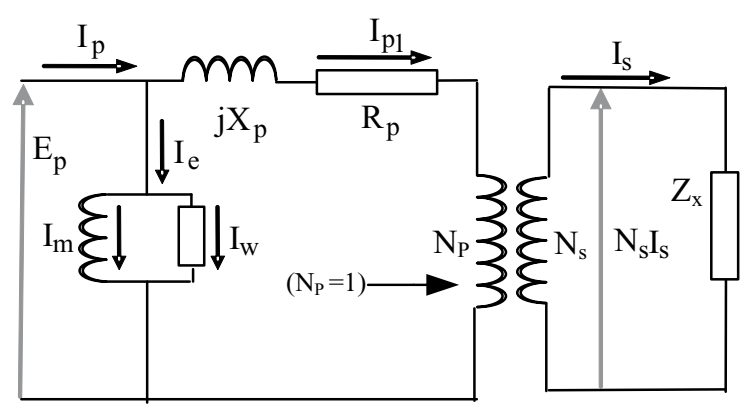

Figure 5 - Equivalent circuit referred to primary side

Figure 6 illustrate that the phase displacement error $(\delta)$ is the different between primary power angle $(\theta)$ and phase angle error of the CT $(\beta)$. Power measurement error due to primary power angle is represented by equation (3) and graphical presentation is given by Figure 7. CT 
error is increased when the primary power factor decreases.

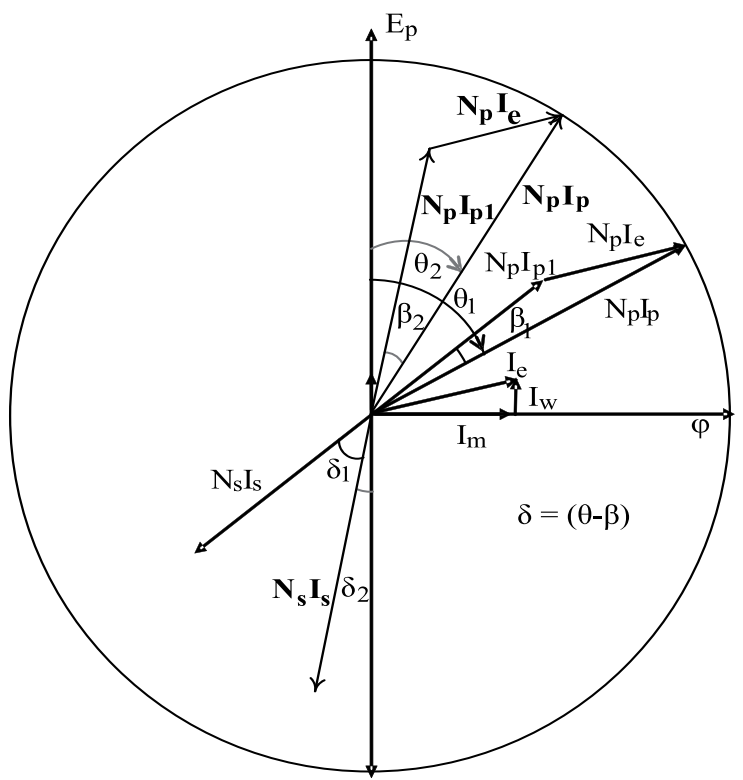

Figure 6 - Vector diagram

$$
\begin{aligned}
& \text { Primary load power factor }=\theta \\
& \text { Phase angle error } \\
& \text { Actual power } \\
& \text { Measured Power } \\
& \mathrm{CT} \text { Error }=\frac{\mathrm{VI} \operatorname{Cos}(\theta-\beta)-\mathrm{VI} \operatorname{Cos} \theta}{\mathrm{VIC} \operatorname{Cos} \theta} \\
& =\operatorname{Cos} \beta+\operatorname{Tan} \theta \cdot \operatorname{Sn} \beta-1
\end{aligned}
$$

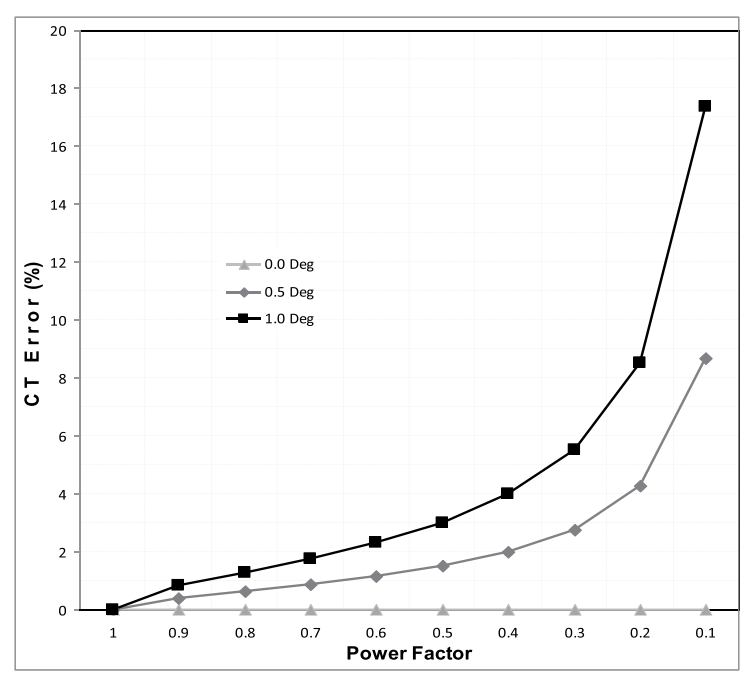

Figure 7 - Power measurement error vs. power factor and phase angle error.

\section{Methodology}

\subsection{Proposed solution for improvement}

Laboratory experiments were performed to analyse the existing metering system from which the chart based solution is proposed for optimum accuracy. Figure 8 shows the 100/5 semi indirect metering model prepared for this experiment.

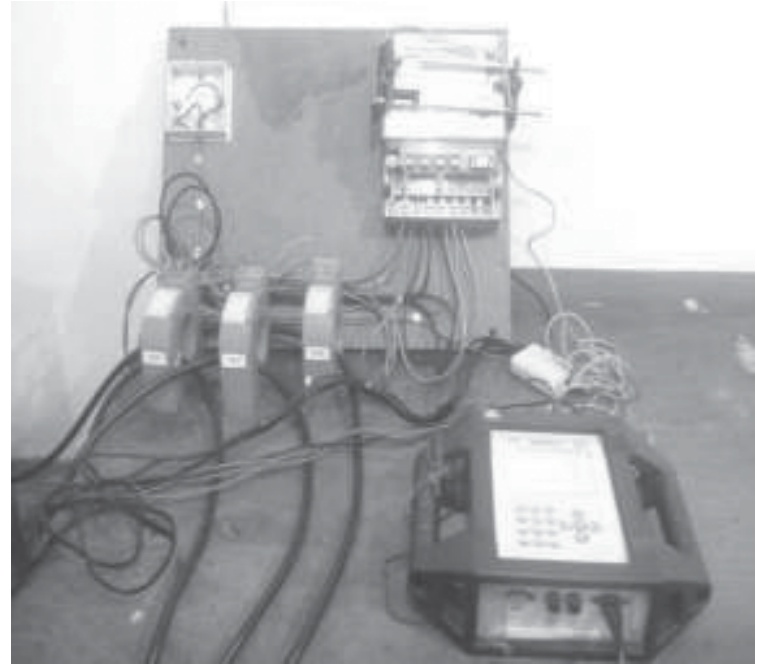

Figure 8 - 100/5 Semi indirect metering model

\subsection{Shifting load to the best performance} range of the $\mathrm{CT}$

It was observed that the best performance range of the CT is $80 \% \mathrm{I}_{n}$ to $120 \% \mathrm{I}_{\mathrm{n}}$. But most of the installations are operating well below this range. IEC regulations states that the performance range of CTs should be maintained up to $120 \% \mathrm{I}_{\mathrm{n}}$ [6]. In this research work all the laboratory experiment were carried out for the operating current range from $10 \% I_{n}$ to $120 \% \mathrm{I}_{\mathrm{n}}$ to give a better feeling to the reader.

\subsection{Appropriate burden matching}

According to the surveyed data (2.4), it can be observed that the opposite burdens of the CTs are very much lower than the rated burden. With this lower burden condition, positive deviation of accuracy is observed. The theoretical analysis shows that the over burden condition may lead to make negative error for metering accuracy. Also, in this research study, it is proposed to vary the lead wire length and the cross sectional area to give the sufficient burden for the CT secondary. The experiments were carried out for different wire lengths, loads and power factor conditions to get an insight feeling to see the metering accuracy variation. Length of the lead wires were increased gradually from 1-8 meters and power factor varied from 1.0-0.8. Results were observed using high accuracy working standard of class 0.02 . A CT of 100/5 having 5VA and a class 0.5 meter of having $0.5 \mathrm{VA}$ burdens were used to execute the test experiment. It is noted that the burden value variation for different wire lengths, cross 
sectional area and secondary CT current values are linearly distributed as shown in Figure 9.

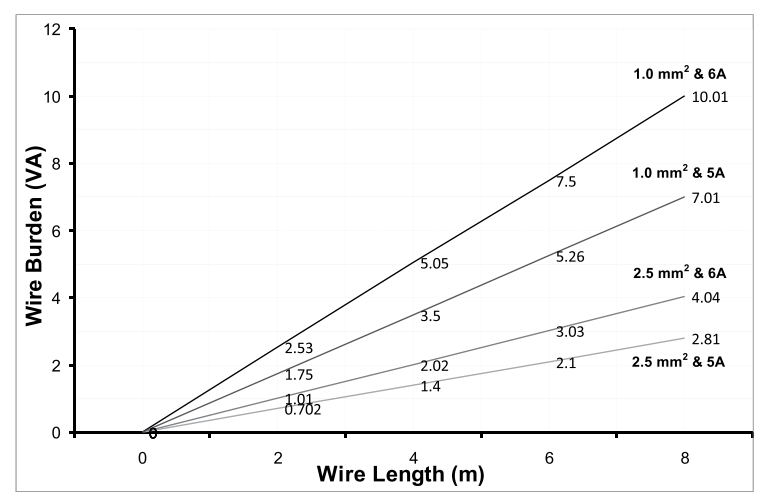

Figure 9-Burdens of lead wires

\section{Test Results}

6.1 Variation of accuracy against wire lengths under different load conditions

The least burden condition of 100/5 semi indirect metering model is observed at the point of $1 \mathrm{~m}$ wire length and $1 \mathrm{~mm}^{2}$ cross sectional area. This is shown in Figure 10. The least burden condition made a positive error which is more than $2 \%$ at the optimum range of operating current of the $\mathrm{CT}$ and at power factor 1.0. When the wire length is increased gradually, the overall error has come down closer to zero and shifted to the negative region. Even though it is not practical in semi indirect scenario, this can be noted when the wire is at $8 \mathrm{~m}$ length as shown in Appendix-B, Figure B4. Also, It can be noticed from Figure 10 that the trend lines of overall accuracy between $80 \%$ and $120 \%$ of nominal current $\mathbf{I}_{\mathbf{n}}$ behaves in more linear manner. Appendix-B, Figure B1 to B4 shows overall accuracy variation of the semi indirect metering system for different wire lengths.

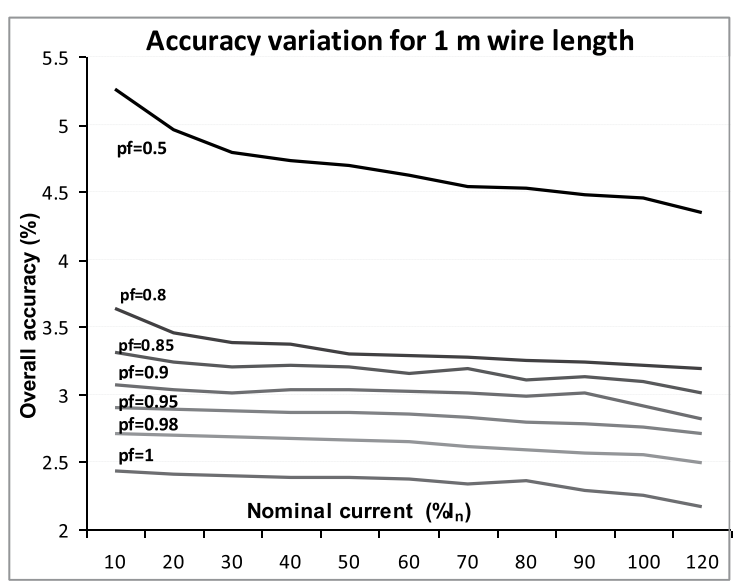

Figure 10 - Accuracy variation for different loads and pf for $1 \mathrm{~m}$ lead wire length
6.2 Variation of accuracy against power factor under different load conditions

Maximum expected overall accuracy of this $100 / 5$ test model would be $1 \%$ due to 0.5 accuracy class of the energy meter and current transformer. But all the results in every state of the experiment were more than $2 \%$. As per the results obtained by the experiments, wire length (burden) and power factor gives significant deviation for the accuracy. At unity power factor condition, its nominal current variation not much effect for the accuracy (around $0.2 \%$ ). Appendix-C, Figure C1 to C5 illustrates above variation for power factor 1 , $0.98,0.95,0.9$ and 0.85 respectively.

\subsection{Variation of accuracy against voltage}

Experiments were carried out to find out the effect of voltage variation for accuracy of analogue and digital meters depicted in Table 3 at base current and $\mathrm{pf}=0.8$. Figure 11 shows that both analogue and digital meter are capable of staying at its class even the voltage varied from $150 \mathrm{~V}$ to $270 \mathrm{~V}$. Static meter remained at a significant value of $0.03 \%$ all over the range. So the effectiveness of voltage variation for the accuracy of semi indirect metering system is negligible.

Table 3 - Meters used for voltage variation

\begin{tabular}{|c|c|c|c|}
\hline Meter type & Model & IBase & Class \\
\hline Analogue & Iskra & $20 \mathrm{~A}$ & 2 \\
\hline Digital & Edmi & $5 \mathrm{~A}$ & 0.5 \\
\hline
\end{tabular}

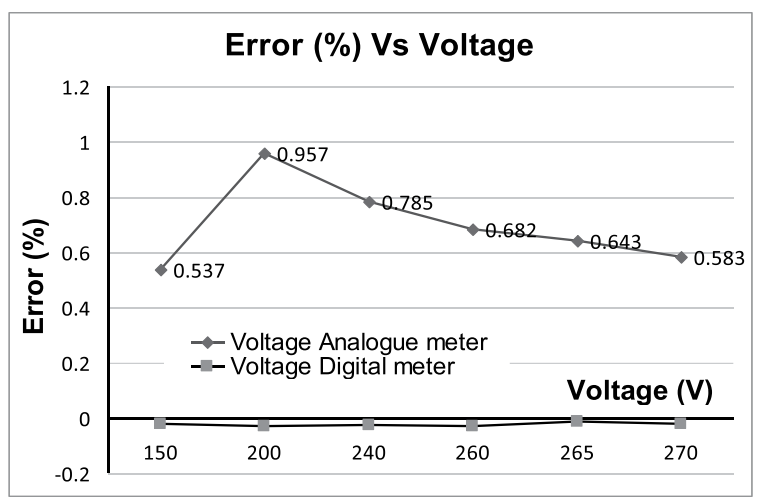

Figure 11 - Accuracy variation for different voltages at base current $\& \mathrm{pf}=\mathbf{0 . 8}$

\subsection{Research outcome}

Several experiments were carried out to analyze the effectiveness of the identified parameters and the behavioural patterns are as shown in Figure 12. It could be noted here that the power factor, nominal current, secondary burden 
(Wire length) were effectively changed the overall accuracy of the semi indirect metering system. Effectiveness of voltage variation is negligible for solid state meter for wide range of voltage variation.

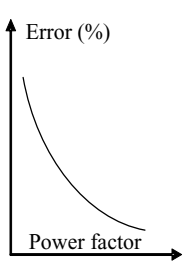

(a)

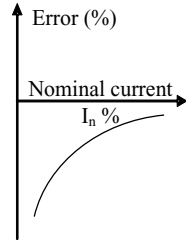

(b)

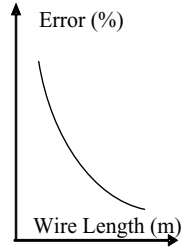

(c)

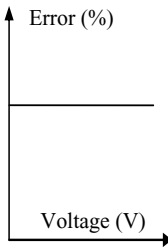

(d)

Figure 12 - Behavioural pattern of the parameters

a) Variation against power factor.

b) Variation against nominal current

c) Variation against wire length.

d) Variation against voltage

\subsection{Component selection criteria}

Before selecting an appropriate wire length for a particular installation, it is important to select the CT ratio for better accuracy. This describes in the flow chart shown in Figure 13. The wire length selection chart of Figure 14 is developed for $0.5 \%$ accuracy only. Here the maximum allowable secondary burden kept at 5VA as mention in CT name plate data. The operating power factor of the installation is highly affected for metering accuracy as discussed earlier. Therefore the wire length selection criterion is restricted on the operating power factor as well as operating current. Hence all the selections are on the safe side and do not fall onto the negative side of the metering error. Flow chart of figure 14 guides the sequence of component selection under two main criterions.

Criteria-1, Maximum allowable wire length for opposite burden of a given $\mathrm{CT}$

Criteria-2, Maximum permissible wire length for optimum accuracy and given pf.

Example:

Contract demand (kVA)

Contract demand current (A)

CT Secondary current (A)

Operating power factor

Burden of the CT (VA)

Wire length (m)
12

$80 \quad 55$

$115.9 \quad 79.7$

$6.0 \quad 4.0$

$0.98 \quad 1.0$

$5 \quad 5$

$3.2 \quad 5.1$

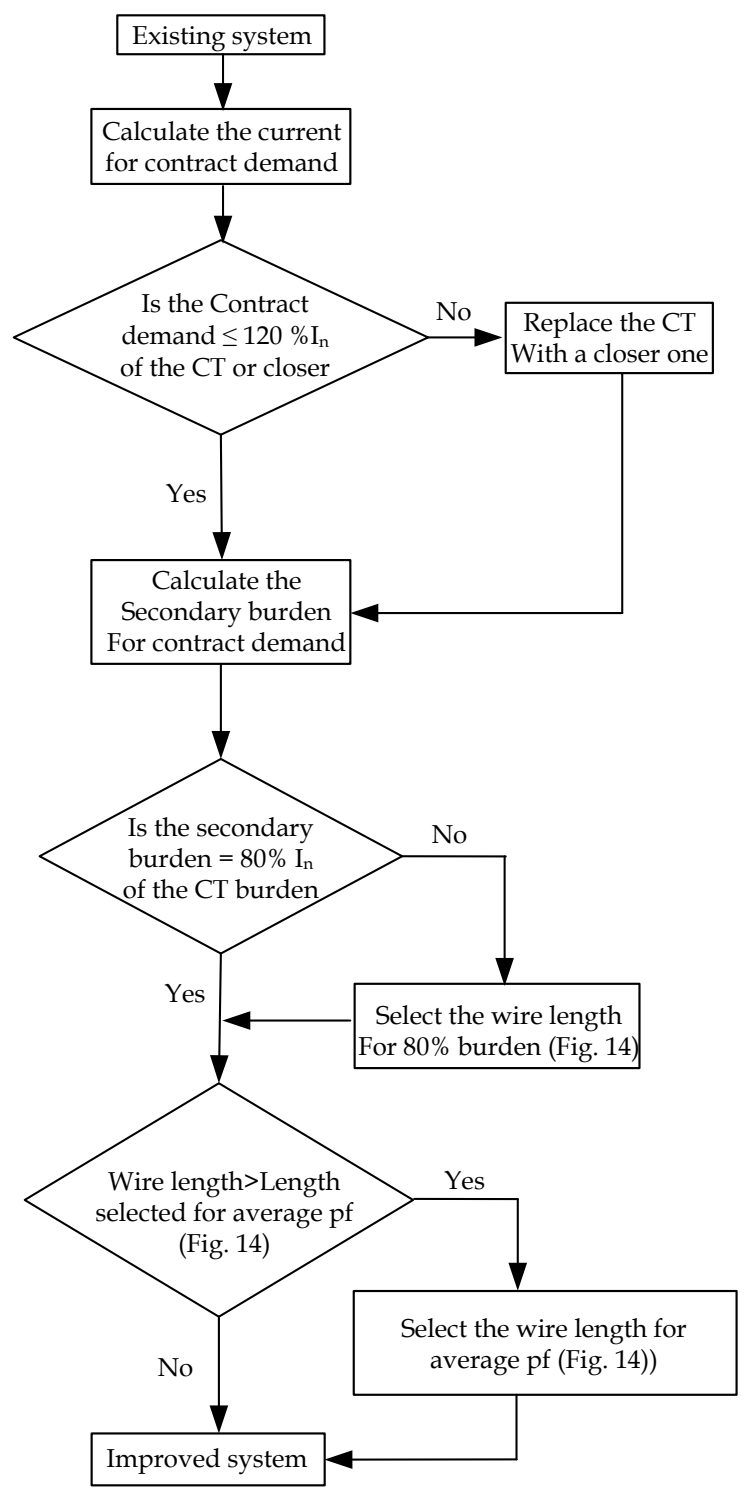

Figure 13 - Flow chart

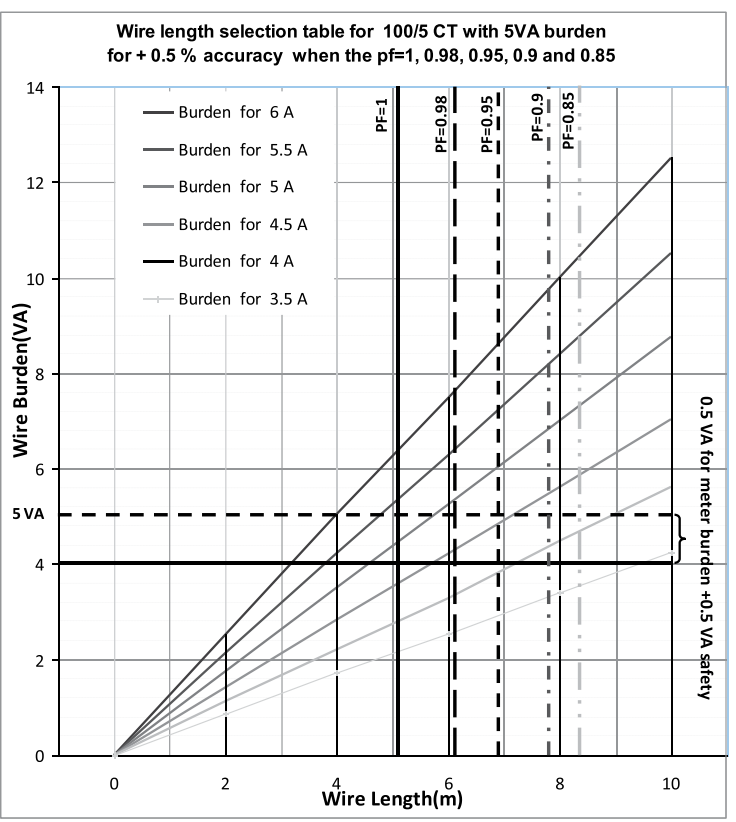

Figure 14 


\section{Conclusion}

One of the major findings derived from this research is that the secondary circuits equipped with solid state energy meters installed under semi indirect metering system are operating at under burden conditions depending on the connected CT with high burden. The actual opposite burdens of the measuring CTs are less than $25 \%$ of the rated burden. Therefore the system operating at under burden condition does not yield to exact measurement of energy thus; an improvement is required. Method of accuracy improvement through maximization of CT performances and appropriate burden matching is proposed here. It explains the methodology of selecting CTs and lead wire lengths carefully while keeping the utility in the safe side. For given measuring CTs, electricity meters and known cross-section, the desired total burden of the secondary circuit can be achieved by an appropriate selection of the conductor length. Moreover the other charts can be developed for more accuracy such as $0.2 \%$ under extreme condition subjected to the p.f. constraints. The attractive feature here is that the low cost of implementation and the least technical expertise requirement. Also reliability is much greater compared to electronic compensation and no routine inspection and periodical calibration are required.

\section{Acknowledgement}

The authors would like to offer their appreciation to Eng. S.R.K. Gamage DGM, Planning \& Development Branch, Distribution Division-1 and Eng. Kamal Perera CE, Development Branch, Distribution Division-1 of CEB for their assistance by providing facilities for this research study and many thanks for the helpful comments suggestions and the guidance provided by Dr. Narendra de Silva of LECO.

\section{References}

1. Ceylon Electricity Board, 2006. Static three phase energy meters accuracy class $1 \mathrm{CT}$ connected meters for remote reading, CEB Standard 071-3:2006

2. Ceylon Electricity Board, 1998. Low voltage ring type measuring current transformers, CEB Standard 027-3:1998
3. Ceylon Electricity Board, STEEL BOXES FOR HOUSING BULK SUPPLY METERS, CEB Standard 050-1997.

4. CIRED, 20 $0^{\text {th }}$ International Conference on electricity distribution, page 0105, Prague, 8-11 June 2009.

5. EDISON ELECTRIC INSTITUTE, 2002, Hand Book for Electricity metering Tenth Edition, EDITION ELECTRIC INSTITUTE, Washington.

6. International Electro Technical commission, 2003-2, Current Transformer, International Standard, IEC 60044-1.

7. International Electro Technical commission, 2003-1, Static meter for active energy, International Standard, IEC 62053-22, First edition.

8. International Electro Technical commission, 2003-1, Electromechanical meters for active energy, International Standards, IEC 62053-11, First edition.

9. http://www.arwtransformers.co.uk/CTInfo, Visited, 14th December 2013.

10. http://www.currenttransformers.co.in, Visited, 14th December 2013.

11. http:// powermetrix.com,Visited, 14th December 2013.

12. http://www.umsmeters.co.uk, Visited, 14th December 2013.

13. http://www.zera.de, Visited, 10th January 2014.

14. http://www.edmi-meters.com, Visited, 12th February 2014. 


\section{Appendix-A}

Table - A1

\begin{tabular}{|c|c|c|c|c|c|}
\hline Customer & Factory-1 & Factory-2 & Factory-3 & Factory-4 & Factory-5 \\
\hline Contract demand (kVA) & 1000 & 630 & 400 & 630 & 630 \\
\hline Average load (kVA) & 300 & 201 & 69 & 320 & 196 \\
\hline Avg. line current (A) & 421 & 293 & 92 & 408 & 277 \\
\hline Average power factor & 0.99 & 0.89 & 0.98 & 0.97 & 0.96 \\
\hline CT type & ITL & ARW & ITL & ITL & ARW \\
\hline CT Accuracy class & 01 & 01 & 01 & 01 & 01 \\
\hline CT ratio & $1600 / 5$ & $1200 / 5$ & $800 / 5$ & $1200 / 5$ & $800 / 5$ \\
\hline CT Burden (VA) & 15 & 15 & 15 & 15 & 15 \\
\hline Meter type & Premier & Premier & Premier & Premier & Edmi \\
\hline Accuracy class & 01 & 01 & 01 & 01 & 01 \\
\hline Meter Burden (VA) & 0.5 & 0.5 & 0.5 & 0.5 & 0.5 \\
\hline Length of Lead wires (m) & $\begin{array}{l}\text { L1 - } 1.1 \\
\text { L2- } 1.0 \\
\text { L3 - } 0.9\end{array}$ & $\begin{array}{c}\text { L1- 1.0 } \\
\text { L2 - } 1.1 \\
\text { L3 - } 1.2\end{array}$ & $\begin{array}{l}\text { L1 }-0.9 \\
\text { L2 - } 1.0 \\
\text { L3 - } 1.1\end{array}$ & $\begin{array}{l}\text { L1 - } 1.0 \\
\text { L2 - } 1.0 \\
\text { L3 - } 1.0\end{array}$ & $\begin{array}{l}\text { L1 }-1.0 \\
\text { L2 }-1.0 \\
\text { L3 }-1.0\end{array}$ \\
\hline Area of the lead wire $\left(\mathrm{mm}^{2}\right)$ & 2.5 & 2.5 & 2.5 & 2.5 & 2.5 \\
\hline Meter error & 0.34 & 0.31 & -0.36 & 0.25 & 0.32 \\
\hline Overall error** & 2. 94 & 3.3 & 3.15 & 3.1 & 3.2 \\
\hline Average current as $\% \mathrm{I}_{n}$ & $26 \%$ & $24.4 \%$ & $11.5 \%$ & $34 \%$ & $34.6 \%$ \\
\hline
\end{tabular}

** including measurement error

\section{Appendix-B}

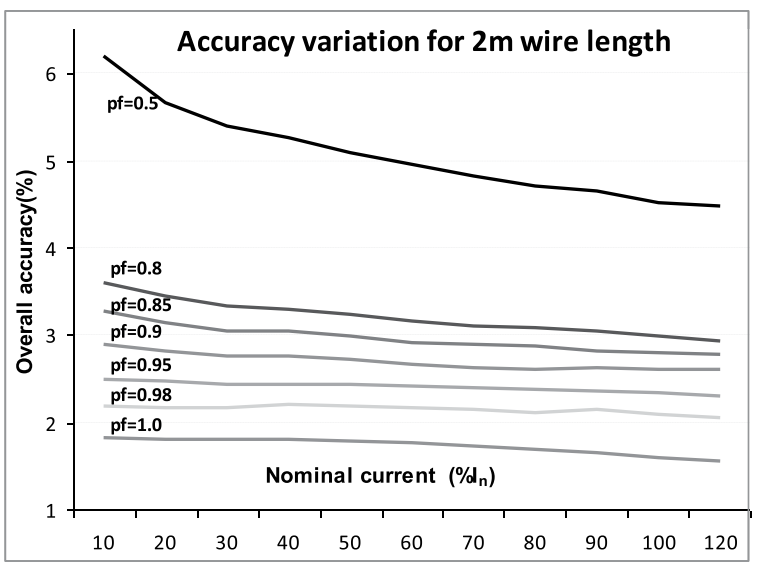

Figure B1

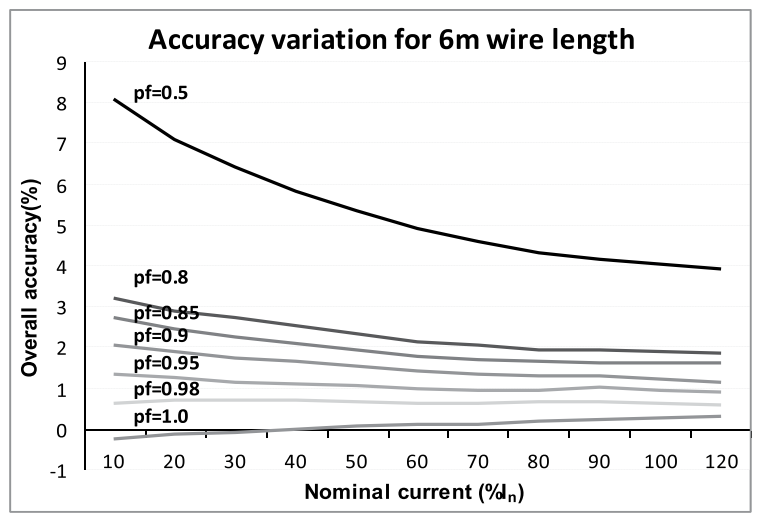

Figure B3

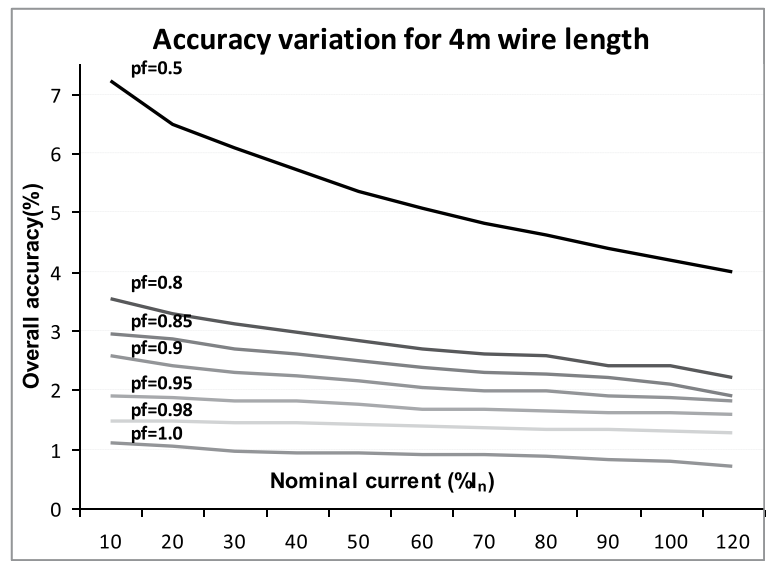

Figure B2

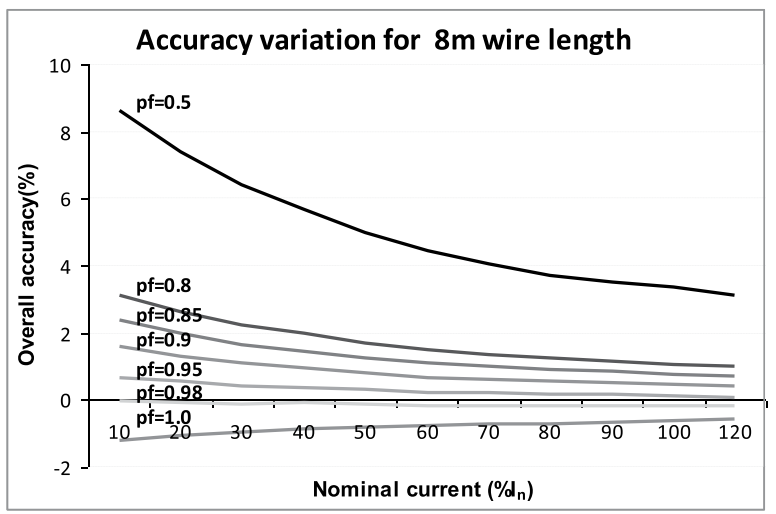

Figure B4 


\section{Appendix-C}

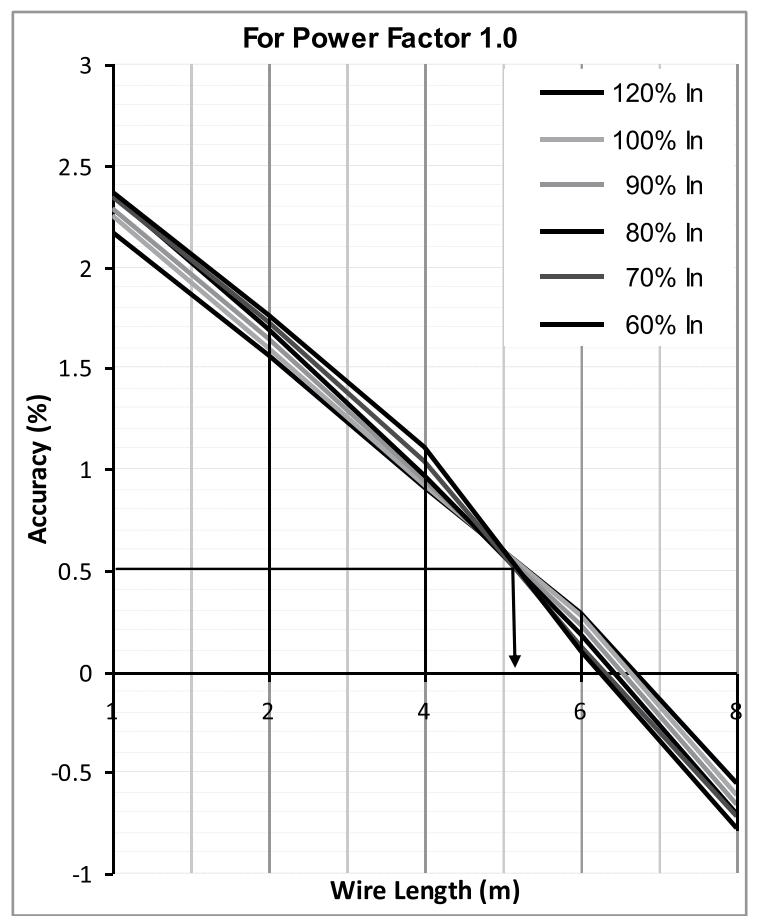

Figure C1

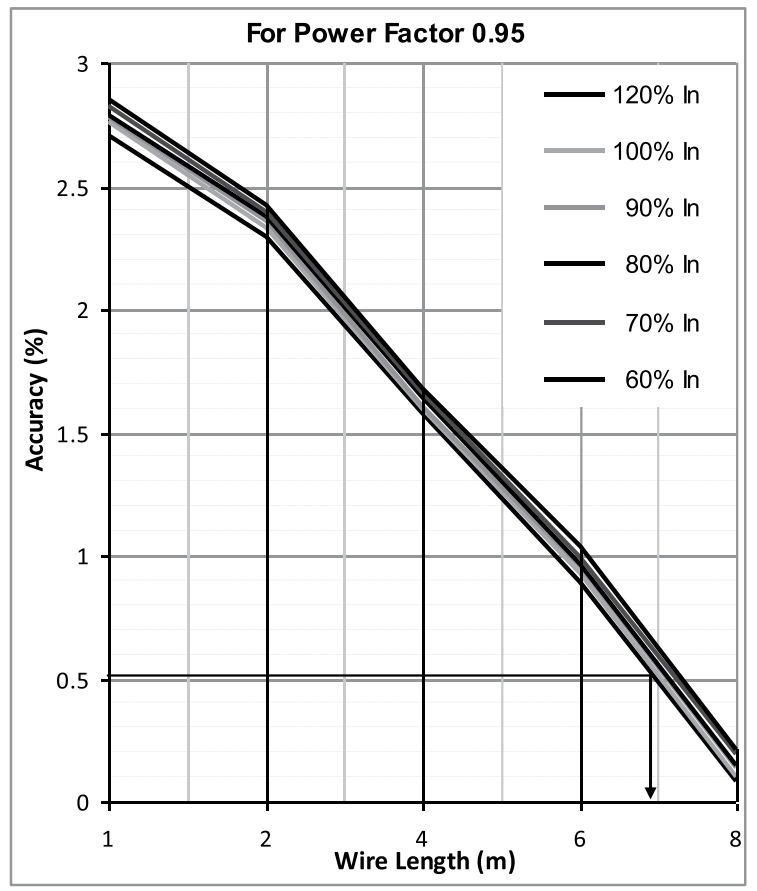

Figure C3

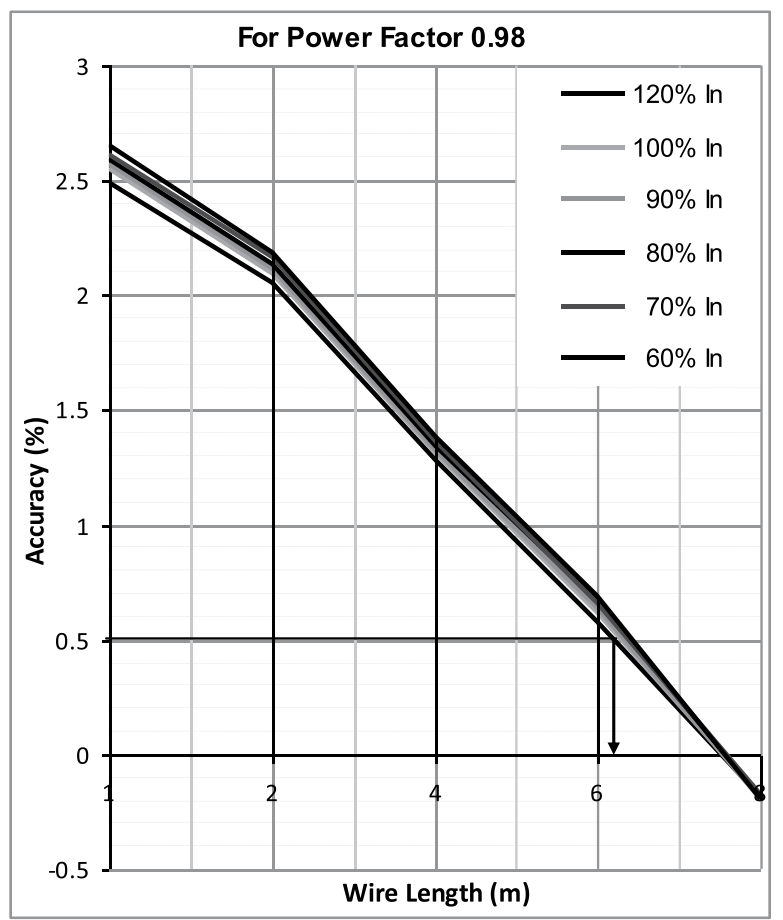

Figure C2

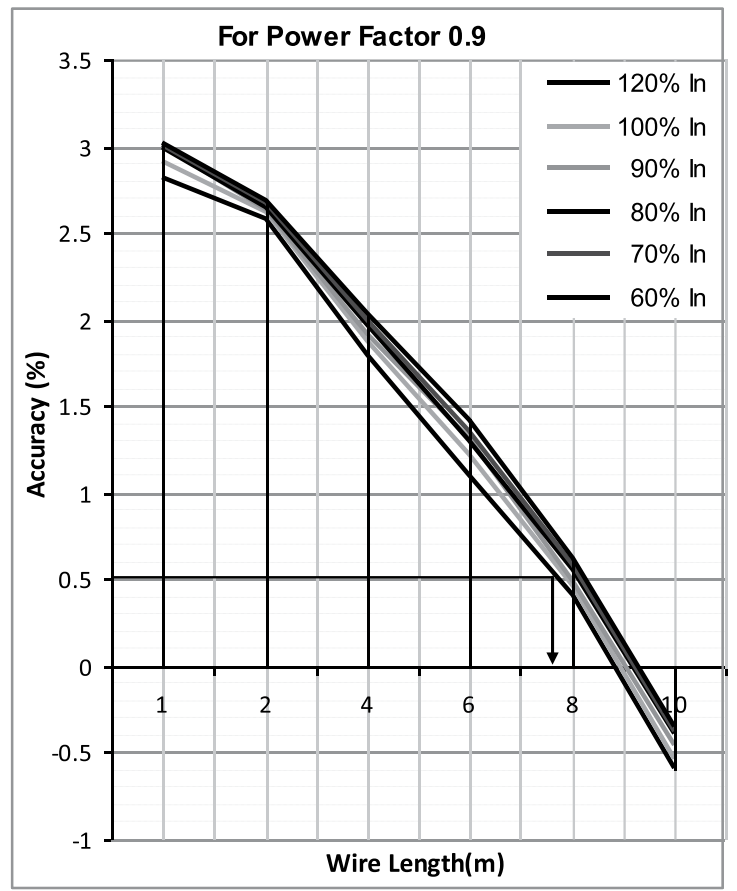

Figure C4 


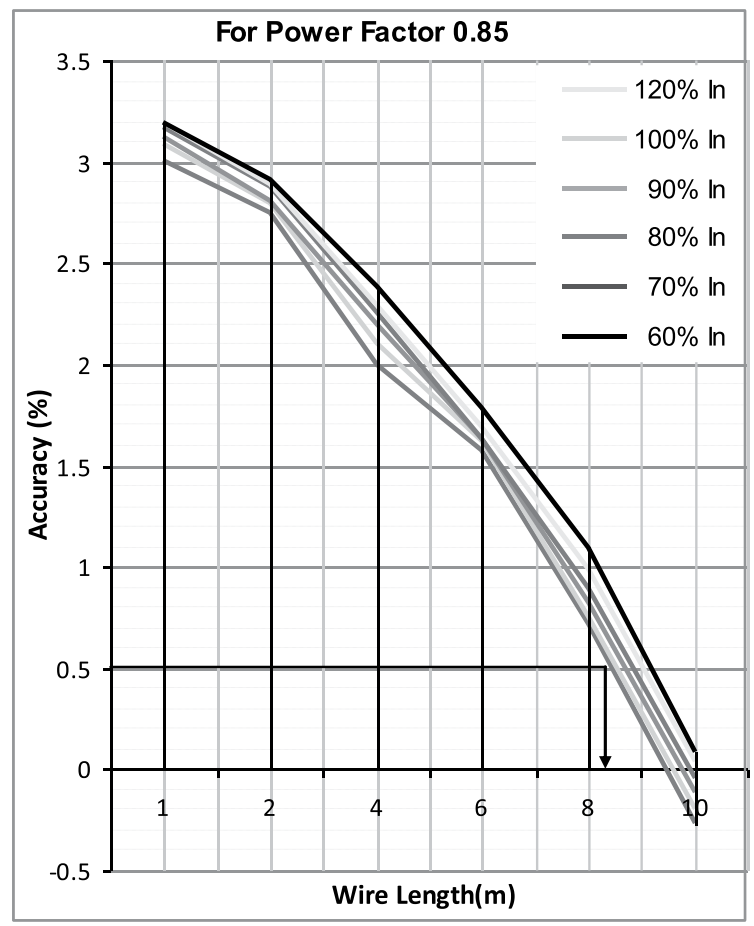

Figure C5 